\title{
NACA 0015 Kanat Profilinin Etrafındaki Akışın Firar Kenarından Akış Emme ile Kontrol Edilmesi
}

\section{Flow Control around NACA 0015 Airfoil by Trailing Edge Flow Suction}

\author{
Tahir Durhasan ${ }^{1 *}$
}

Geliş / Received: 08/07/2019

Revize / Revised: 19/08/2019

Kabul / Accepted: 05/09/2019

$\ddot{O}$

z- Bu çalış̧mada, kanat firar kenarında uygulanan akış emme yönteminin NACA 0015 kanat profilinin aerodinamik performansı üzerine etkileri sayısal çalışma ile araştırılmıştır. Sayısal çözümler Reynolds sayısının $R e=48000$ değerinde $k-k_{L}-\omega$ transition model kullanılarak ANSYS Fluent tarafindan gerçekleştirilmiştir. Üç farklı emme oranı $(\theta=0.05,0.1$ ve 0.2$)$ dört farklı kanat hücum açısında $\left(\alpha=2^{\circ}, 4^{\circ}, 6^{\circ}\right.$ ve $\left.8^{\circ}\right)$ test edilmiştir ve elde edilen bulgular kontrolsüz durum ile kıyaslanmıştır. Düşük hücum açılarında laminer ayrılma kabarcığı önemli ölçüde kontrol edilmiştir. Hücum açılarının $\alpha=2^{\circ}$ ve $4^{\circ}$ değerlerinde $\operatorname{artan}$ emme oranı ile $C_{L} / C_{D}$ oranının kontrolsüz durumun 2.4 katına kadar arttığı gözlemlenmiştir. Ancak hücum açısının $\alpha=8^{\circ}$ değerinde $C_{L}$ artması ile birlikte $C_{D}$ 'nin de artmasından dolayı $C_{L} / C_{D}$ oranının kontrolsüz duruma göre önemli ölçüde artmadığı gözlemlenmiştir.

Anahtar Kelimeler- Akış Kontrolü, Düşük Reynolds Sayılı Akış, Kanat Profili, Laminer Ayrılma Kabarcığı

\begin{abstract}
$A$ bstract- In this study, the effect of flow suction at trailing edge on aerodynamic performance of NACA 0015 airfoil was investigated, numerically. Numerical solutions were performed by ANSYS Fluent using k-kL- $\omega$ transition model at Reynolds number of $R e=48000$. Three different suction ratios $(\theta=0.05,0.1$ ve 0.2$)$ were tested at four different angles of attacks $\left(\alpha=2^{\circ}, 4^{\circ}, 6^{\circ}\right.$ ve $\left.8^{\circ}\right)$ and obtained results were compared with the base case. Laminar separation bubble was controlled significantly at low angles of attack. It was observed that $\mathrm{C}_{L} / \mathrm{C}_{\mathrm{D}}$ increases up to 2.4 times $C_{L} / C_{D}$ of the base case with the increasing suction ratio at $\alpha=2^{\circ}$ ve $4^{\circ}$. On the other hand, it was observed that the $C_{L} / C_{D}$ did not alter significantly in comparison with the base case at $\alpha=8^{\circ}$ since $C_{D}$ also increases while $\mathrm{C}_{\mathrm{L}}$ increases.
\end{abstract}

Keywords- Flow Control, Low Reynolds Number Flow, Airfoil, Laminar Separation Bubble

1*Sorumlu yazar iletișim: tdurhasan@atu.edu.tr (https://orcid.org/0000-0001-5212-9170)

Havacılık ve Uzay Mühendisliği, Adana Alparslan Türkeş Bilim ve Teknoloji Üniversitesi, Adana, Türkiye 


\section{GİRIŞ}

Düşük Reynolds sayılarında çalışan dikey rüzgar türbinleri ve mikro insansız hava taşıtları gibi araçlarda kanat aerodinamik performansını etkileyen en önemli faktör laminer ayrılma kabarcığıdır. Farklı kanat profillerinde laminer ayrılma kabarcığının oluşumu ve davranışları Ricci ve Montelpare [1], Zhang vd. [2], Genç vd. [3], Juanmian vd. [4] ve Demir ve Genç [5] tarafından ayrıntılı bir biçimde araştırılmıştır. Ayrıca Genç vd. [6] tarafından düşük Reylonds sayılarındaki kanat aerodinamiği üzerine kapsamlı bir derleme sunulmuştur. Laminer ayrılma kabarcığının neden olduğu kanat kaldırma katsayısındaki $\left(\mathrm{C}_{\mathrm{L}}\right)$ düşüş ve sürükleme katsayısındaki $\left(\mathrm{C}_{\mathrm{D}}\right)$ artış kanat aerodinamik performansını azaltmaktadır. Bu etkilerden kaçınmak için kanat efradındaki akışa aktif ve pasif olmak üzere iki ana başlık altında toplanan çeşitli kontrol yöntemleri geliştirilmektedir. Aktif ve pasif kontrol yöntemleri arasındaki en temel farklılık aktif akış kontrol yöntemlerinin harici bir enerjiye ihtiyaç duymasıdır.

Huang vd. [7] NACA 0012 kanat profilinin emme yüzeyinden gerçekleştirdikleri jet emme ve üflemenin akış kontrolü üzerine etkisini araştırmışlardır. Reynolds sayısının $R e=500000$ ve kanat hücum açısının $18^{\circ}$ değerlerinde yapılan sayısal çalışma bulguları emme ve üflemenin akış kontrolü üzerine etkisinin jetin kanat emme yüzeyindeki konumuna bağlı olarak farklılık gösterdiğini ortaya koymuşlardır. Kaldırma katsayısını arttırmak için, jet emme işleminde hücum kenarına yakın konumlandırılan durumların, jet üfleme işleminde ise firar kenarına yakın olan durumların daha iyi olduğunu göstermişlerdir. Johari vd. [8] NACA 634-021 kanat profilinin hücum kenarında oluşturdukları çıkıntıların kanat aerodinamiği üzerine etkisini araştırmışlardır. Elde edilen bulgular çıkıntısız kanat ile kıyaslandığında kaldırma katsayısının azaldığı ancak stol açısının ertelendiğini göstermiştir. Genç vd. [9] yaptıkları sayısal çalışma ile emme ve üfleme yönetmelerinin NACA 2415 kant profilinin aerodinamik performansına etkisini araştırmışlardır. Elde edilen bulgular sadece emme ya da üfleme yapmanın laminer ayrılma kabarcı̆̆ını tamamen yok edemediğini ancak emme ve üflemenin eşzamanlı olarak yapılması durumunda ayrılma kabarcı̆̆ı tamamen yok edilebildiğini göstermiştir. Yousefi ve Saleh [10] firar kenarından yapılan jet üfleme yönteminin NACA 0012 kanat profili etrafindaki akış kontrolü üzerine etkisini araştırmışlardır. Sayısal çalışmalardan elde edilen bulgular jet genişliğinin, hız büyüklüğünün ve yönünün önemli parametreler olduğunu ve seçilen uygun parametreler ile kaldırma katsayının sürüklenme katsayısına oranının \%17'ye kadar arttırılabileceğini göstermişlerdir. Açıkel ve Genç [11] ve Genç vd. [12] yaptıkları çalışmalar ile NACA 2415 kanat profilinde laminer ayrılma kabarcığının akustik uyarım yöntemi ile kontrol edilebileceğini gösterdiler. Siozos-Rousoulis vd. [13] yaptığı sayısal çalışma ile NACA 0012 kanat profilinin gelen akış yönüne konumlandırılan dönen küçük silindirin aerodinamik gürültünün bastırılması üzerine etkisini incelemiştir. Elde edilen bulgular dönen küçük silindirin kanat girdap caddesini bastırmasından ve ötelemesinden dolayı akustik emisyonların azaltıldığını göstermişlerdir. Akbıyık vd. [14,15] yaptıkları deneysel çalışmalar ile NACA 0015 kanat profilinin emme yüzeyine konumlandırılan DBD plazma aktüerler yardımı ile kaldırma katsayısının arttırılırken sürüklenme katsayısının azaltılabileceğini göstermişlerdir. Açıkel ve Genç [16] NACA 4412 kanat profilinde laminer ayrılma kabarcığının esnek kısmi membran ile kontrol edilmesini düşük Reynolds sayılarında çalıştırlar. Elde edilen deneysel bulgular esnek kısmi membran kullanımı ile laminer ayrılma kabarcı̆̆ının bastırıldığını, kaldırma katsayısının arttığını ve sürüklenme katsayısının azaldığını göstermiştir. Genç vd [17] NACA 4412 kanat profili emme yüzeyinde oluşturdukları pürüzlülüğünün kanat aerodinamiği üzerine etkisini Reynolds sayısının $\mathrm{Re}=25000$ ile 50000 değerleri arasında araştırmışlardır. Deneysel ve sayısal çalışmalardan elde edilen bulgular oluşturulan pürüzlülüğünün kaldırma katsayısını \%14 arttırmasının yanı sıra stol açısını $14^{\circ}$ 'den $20^{\circ}$ ye ertelediğini göstermiştir.

Bu çalışmada, NACA 0015 kanat profilinin firar kenarına uygulanan akış emme yönteminin kanat aerodinamiği üzerine etkileri Reynolds sayısının $\mathrm{Re}=48000$ değerinde sayısal olarak araştırılmıştır. Akış emme yönteminin etkisini ortaya koyabilmek için elde edilen bulgular ayrıca emme işlemin yapılmadığı (kontrolsüz) kanat sonuçları ile kıyaslanmıştır. Akış emme yönteminin düşük kanat hücum açısı değerlerinde kanat aerodinamik performansını artırdığı ancak yüksek hücum açılarında önemli bir etkisinin olmadığı görülmüştür.

\section{MATERYAL VE METOT}

Sayısal çözümler Reynolds sayısının $\mathrm{Re}=48000$ değerinde 3 denklemli $\mathrm{k}-\mathrm{k}_{\mathrm{L}}-\omega$ Transition türbülans modeli kullanılarak ticari yazılım (ANSYS Fluent 17.2) yardımı ile gerçekleştirilmiştir. Walters ve Cokljat [18] tarafından geliştirilen bu model türbülans kinetik enerji $(\mathrm{k})$, laminer kinetik enerji $\left(\mathrm{k}_{\mathrm{L}}\right)$ ve özgün dağılma oranı ( $\omega)$ denklemlerini bünyesinde barındırır. Türbülans model ile ilgili ayrıntılı bilgi ve matematiksel denklemler ANSYS Fluent teori rehberinde [19] verilmiştir. Düşük Reynolds sayılarında $\mathrm{k}-\mathrm{k}_{\mathrm{L}}-\omega$ Transition türbülans modelinin kanat profilleri etrafındaki akışı tahmin etmede başarılı olduğu Genç vd. [20], Genç vd. [9] ve Choudhry vd. [21] tarafindan gösterilmiştir. 
İki boyutlu NACA 0015 kanat profili, etrafındaki akış alanı ve yapısal ağ (C tipi) ANSYS Workbench'de oluşturulmuştur. Akış alanı kanat profilinin önünde, alt ve üst bölgelerinde veter boyunun 10 katı kadar, arkasında ise 20 katı kadar genişlemektedir. Kanat profiline "Kaymama koşulu (No-slip)" ve akış alanı dış yüzeyine "basınç uzak alan (pressure-far field)" sınır şartı uygulanmıştır. Sayısal çözümlerde Kapalı formülasyon Akı tipi AUSM ayrıklaştırma ikinci derecen yukarı yönlü formülasyon kullanılmıştır. Akış emme genişliği, $h$ veter uzunluğunun $\mathrm{h}=\% 3.5$ 'i büyüklüğünde seçilmiştir ve kanat firar kenarına konumlandırılmıştır. Kanat firar kenarında gerçekleştirilen emme yöntemi için kanat üzerindeki emme profiline "basınç uzak alan (pressure-far field)" sınır şartı uygulanmıştır. Akış emme oranı, $\theta=V j e t / U_{\infty}$ şeklinde tanımlanmıştır. Burada Vjet kanat firar kenarında gerçekleştirilen akış emme hızını, $U_{\infty}$ ise serbest akım hızını ifade etmektedir. Sayısal çözümler $\theta=0.05,0.1$ ve 0.2 değerleri için gerçekleştirilmiştir. Ayrıca bütün emme oranları için kanat hücum açısının $\alpha=2^{\circ}, 4^{\circ}, 6^{\circ}$ ve $8^{\circ}$ değerlerinde sayısal çözümler gerçekleştirilmiştir. Akış emme yönü, $V_{\text {jet }}$ bütün kanat hücum açıları için veter çizgisine dik olacak şekilde konumlandırılmıştır. Kanat profilinin akış alanındaki konumu, parametrelerin şematik gösterimi ve ağ yapısı şekil 1' de sunulmuştur.

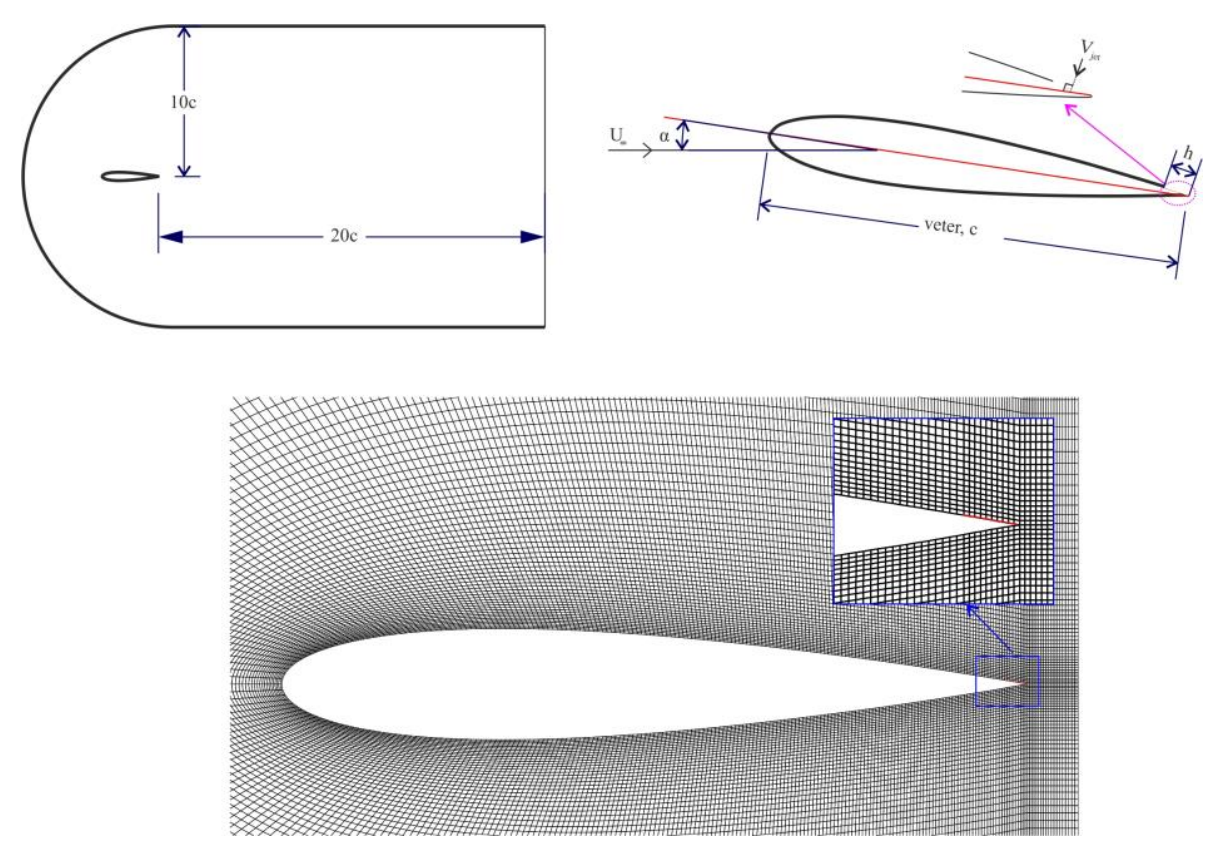

Şekil 1. Kanat profilinin akış alanındaki konumu, parametrelerin şematik gösterimi ve ağ yapısı

Sayısal çözümlerin ağdan bağımsızlığını göstermek için kanat hücum açısının $\alpha=4^{\circ}$ değerinde NACA 0015 etrafındaki akış (kontrolsüz durum) 6 farklı hücre sayısında çözüm gerçekleştirilmiştir ve kaldırma katsayısının, $C_{L}$ farklı düğüm sayıları ile değişimi şekil 2a'da sunulmuştur. Elde edilen bulgular 68200 hücre sayısının yeterli olduğunu göstermiştir ve ayrıca bu hücre sayısında $\mathrm{y}^{+}$değeri 1 'in altında bulunmuştur. Ayrıca, emme yönteminin uygulandığı bütün sayısal çözümlerde de $\mathrm{y}^{+}$değerinin 1'in altında olmasına dikkat edilmiştir. Bunun yanı sıra, sayısal çözümlerin doğruluğunu göstermek için kontrolsüz durumda farklı hücum açılarında elde edilen $C_{L}$ değerleri Akbıyık vd. [15] tarafından Reynolds sayısının $R e=48000$ değerinde açık çevrim rüzgar tünelinde kuvvet ölçümlerinden elde edilen sonuçlar ile kıyaslanmıştır ( şekil 2b). Sayısal çözümlerden elde edilen verilerin tutunma kaybı (stol) açısına kadar $\left(\alpha=10^{\circ}\right)$ deneysel veriler ile çok iyi örtüştüğü görülmüştür. 

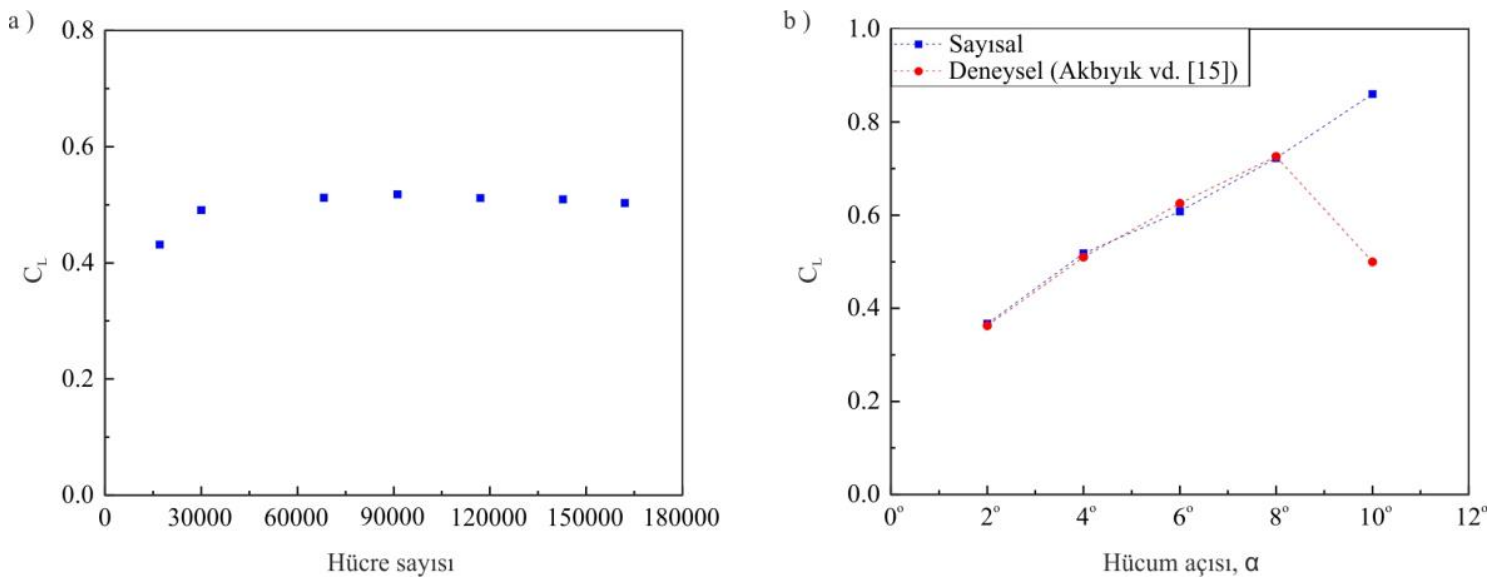

Şekil 2. Kontrolsüz durum için $\mathrm{C}_{\mathrm{L}}$ 'nin a ) farklı hücre sayıları ile değişimi b ) deneysel sonuçlar ile kıyaslanması

\section{BULGULAR VE TARTIŞMA}

Farklı akış emme oranları için $C_{L}$ 'nin hücum açısı ile değişimleri şekil 3a'da sunulmuştur. Bütün hücum açıları için akış emme yönteminin $\mathrm{C}_{\mathrm{L}}$ üzerinde etkili olduğu görülmüştür. Hücum açısının $\alpha=2^{\circ}$ değerinde, emme oranı $\theta=0.05$ 'de $C_{L}$ kontrolsüz durumun 1.5 katı, $\theta=0.2$ 'de ise yaklaşık 2 katı değerine ulaşmıştır. Özellikle $\theta=0.05$ ve 0.1 değerlerinin $C_{L}$ üzerindeki etkileri artan hücum açısı ile azalmaktadır. Hücum açısının $\alpha=8^{\circ}$ değerinde, $C_{L}$ değerleri kontrolsüz durum ile kıyaslandığında $\theta=0.05$ ve 0.1 için sırası ile \%4 ve \%14 arttığ gözlemlenmiştir. Emme oranı $\theta=0.2$ değeri için ise elde edilen $C_{L}$ değeri kontrolsüz durumun yaklaşık 2 katına ulaştığı görülmüştür. Kanat aerodinamiğinde önemli parametrelerden bir tanesi de kaldırma katsayısının sürüklenme katsayısına oranının belirlenmesidir. Şekil 3b'de farklı emme oranları için $\mathrm{C}_{\mathrm{L}} / \mathrm{C}_{\mathrm{D}}$ oranlarının hücum açıları ile değişimi sunulmuştur. Hücum açısının $\alpha=2^{\circ}$ değerinde $C_{L} / C_{D}$ oranının, akış emme oranları $\theta=0.05,0.1$ ve 0.2 için kontrolsüz durumda elde edilen değerin sırası ile 1.6, 1.9 ve 2.4 katına ulaşmıştır. Artan hücum açısı ile laminer ayrılma kabarcığı kanat hücum kenarına yaklaşmaktadır. Emme işlemi ise firar kenarında olduğu için laminer ayrılma kabacığını düşük hücum açıları kadar elimine edememektedir ve emme işlemi kanat yüzeyinde flap gibi davranarak $C_{D}$ değerinin artmasına sebep olmaktadır. Bu neden ile $C_{L} / C_{D}$ oranı artan hücum açısı ile azalmaktadır. Her ne kadar $\mathrm{C}_{\mathrm{L}} / \mathrm{C}_{\mathrm{D}}$ oranı kontrolsüz duruma kıyasla çok değişmese de artan $\mathrm{C}_{\mathrm{L}}$ değeri hava aracı kalkışı gibi durumlar için elverişli olabilir. Akış emme oranı $\theta=0.05$ için elde edilen $C_{L} / C_{D}$ oranının kontrolsüz durumdan daha küçük olmasına rağmen $\theta=0.2$ için elde edilen değer kontrolsüz durumdan \%19 daha fazla olduğu görülmüş̧ür.
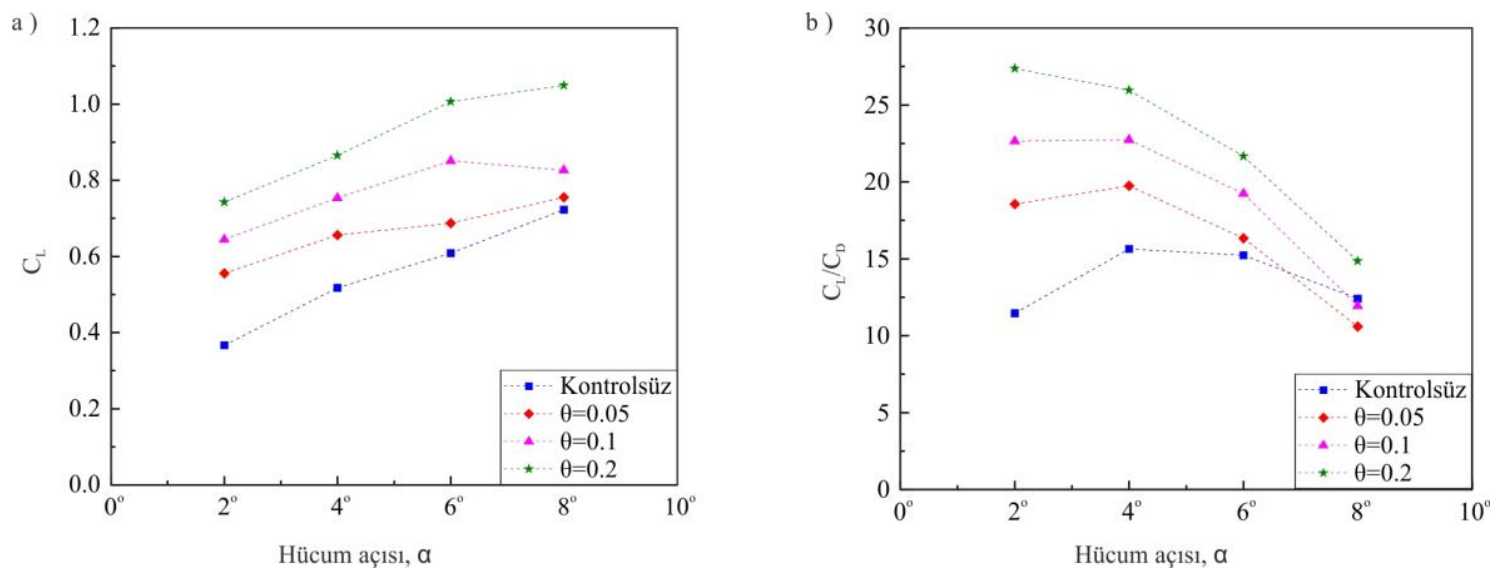

Şekil 3. Farklı akış emme oranları için a ) $C_{L}$ 'nin hücum açıları ile değişimi b ) $C_{L} / C_{D}$ 'nin hücum açıları ile değişimi

Akış emme oranlarının basınç katsayısı dağılımı üzerindeki etkisini göstermek için şekil 4'de farklı hücum açılarında basınç katsayısının, $C_{P}$ kanat yüzeyindeki dağılımları sunulmuştur. Şekil 4'de sunulan dağılımlarda $-C_{P}$ değerleri kullanılmıştır. $C_{P}$ dağılımı kanadın aerodinamik performansının belirlenmesindeki önemli parametrelerden biridir. -Cp dağılımında üst tarafta oluşan kambur biçimindeki eğri laminer ayrılma 
kabarcığını, eğrinin aşağı doğru yönelmesi ise akışın türbülansa geçişini ifade etmektedir. Kontrolsüz durum için elde edilen $C_{P}$ dağılımları artan hücum açısı ile emme basıncının arttığını göstermiştir. Bu neden ile $C_{L}$ artan hücum açısı ile artmaktadır. Hücum açısının $\alpha=2^{\circ}$ değerinde artan emme oranı ile kanat yüzeyindeki emme basıncının arttığı gözlemlenmiştir. Özellikle hücum açısının $\alpha=4^{\circ}$ ve $6^{\circ}$ değerlerinde kambur biçimindeki eğrinin küçülmesi ve eğrinin kontrolsüz duruma göre daha önce aşağı doğru yönelmesi kontrol uygulanan durumlar için laminer ayrılma kabarcığının kısaldığını ve akışın türbülansa daha erken geçtiğini açıkça göstermektedir. Hücum açısının $\alpha=8^{\circ}$ değerinde ise emme oranı $\theta=0.2$ için emme basıncı kontrolsüz durum ile kıyaslandığında daha yüksek değerlere sahip olmasına rağmen ayrılma kabarcı̆̆ının boyutunun ve akışın türbülansa geçiş mesafesinin değişmediği gözlemlenmiştir.
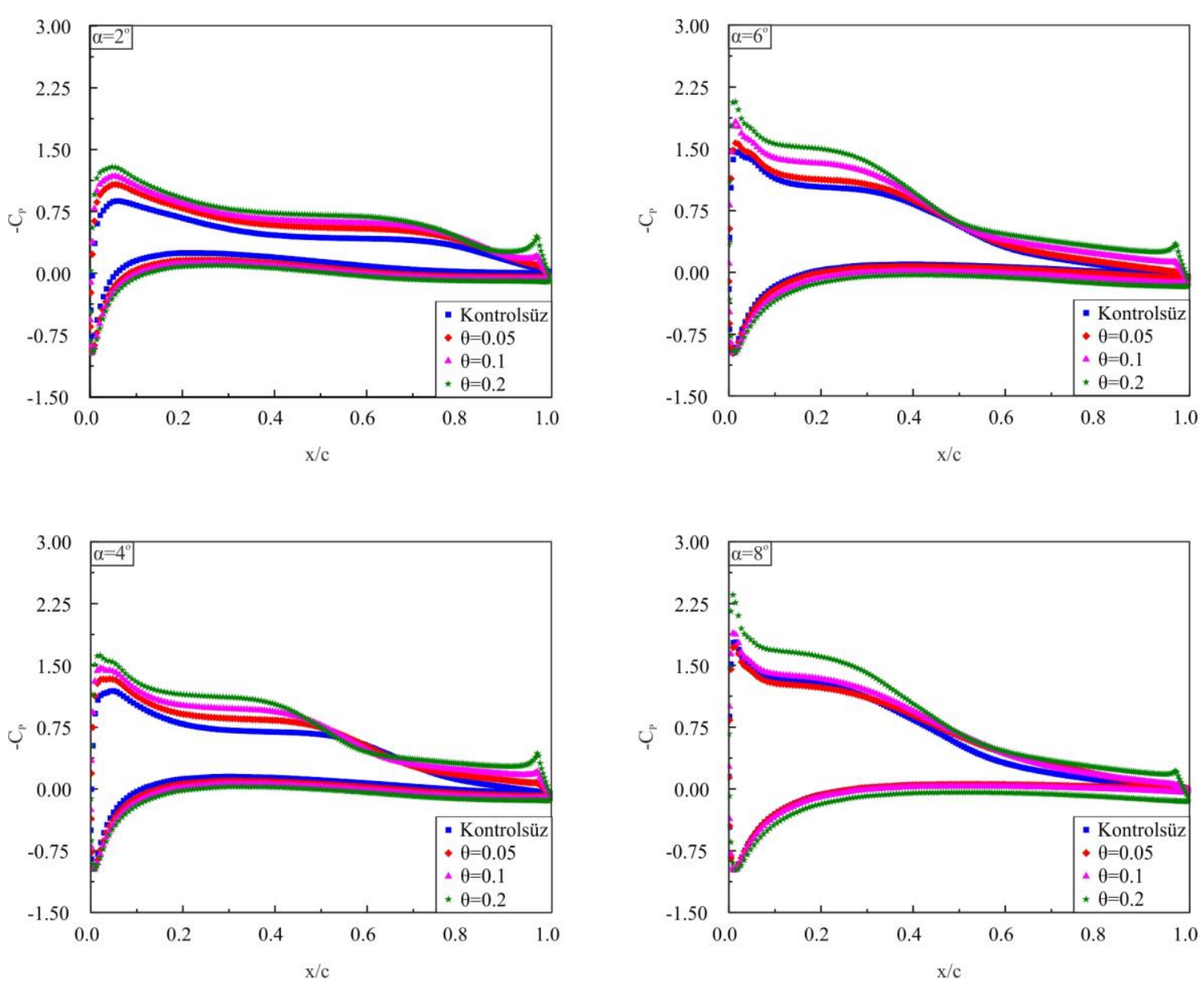

Şekil 4. Farklı hücum açılarında farklı akış emme oranları için basınç dağılımları

Şekil 5'de farklı hücum açıları ve akış emme oranları için kanat etrafındaki akım çizgeleri sunulmuştur. Kontrolsüz durum için hücum açısının $\alpha=2^{\circ}$ değerinde kanadın emme ve basınç yüzeylerinde firar kenarı ayrılmasının oluştuğu ve hatta bu iki ayrılma birleşmiş, yani ayrılma kabarcığı yüzeye tutunamamıştır. Ancak akış emme yönteminin uygulanması ile bu iki ayrılmanın bir biri ile olan iletişimi koparılmıştır. Ayrıca artan akış emme oranı ile emme yüzeyinde meydana gelen ayrılmanın boyutu küçülmüştür. Kontrolsüz durum için hücum açısının $\alpha=4^{\circ}$ değerinde ise kanadın emme yüzeyinde laminer ayrılma kabarcığının oluştuğu ve ayrıca artan hücum açısı ile kabarcığın hücum kenarına yaklaştığı gözlemlenmiştir. Hücum açılarının $\alpha=4^{\circ}$ ve $6^{\circ}$ değerlerinde uygulanan akış emme yöntemi hem laminer ayrılma kabarcı̆̆ının kısalmasına hem de kabarcı̆̆ın hücum kenarına yaklaşmasına neden olmuştur. Hücum açısının $\alpha=8^{\circ}$ değerinde kontrolsüz durum ile kıyaslandığında akış emme oranı $\theta=0.05$ 'de ayrılma kabarcığının uzamasına neden olmuştur. Bundan dolayı da $\mathrm{C}_{\mathrm{L}} / \mathrm{C}_{\mathrm{D}}$ oranı düşmektedir. Akış emme oranı $\theta=0.2$ 'de ise kabarcık boyutunu kontrolsüz duruma göre kısaldığ görülmüştür. 

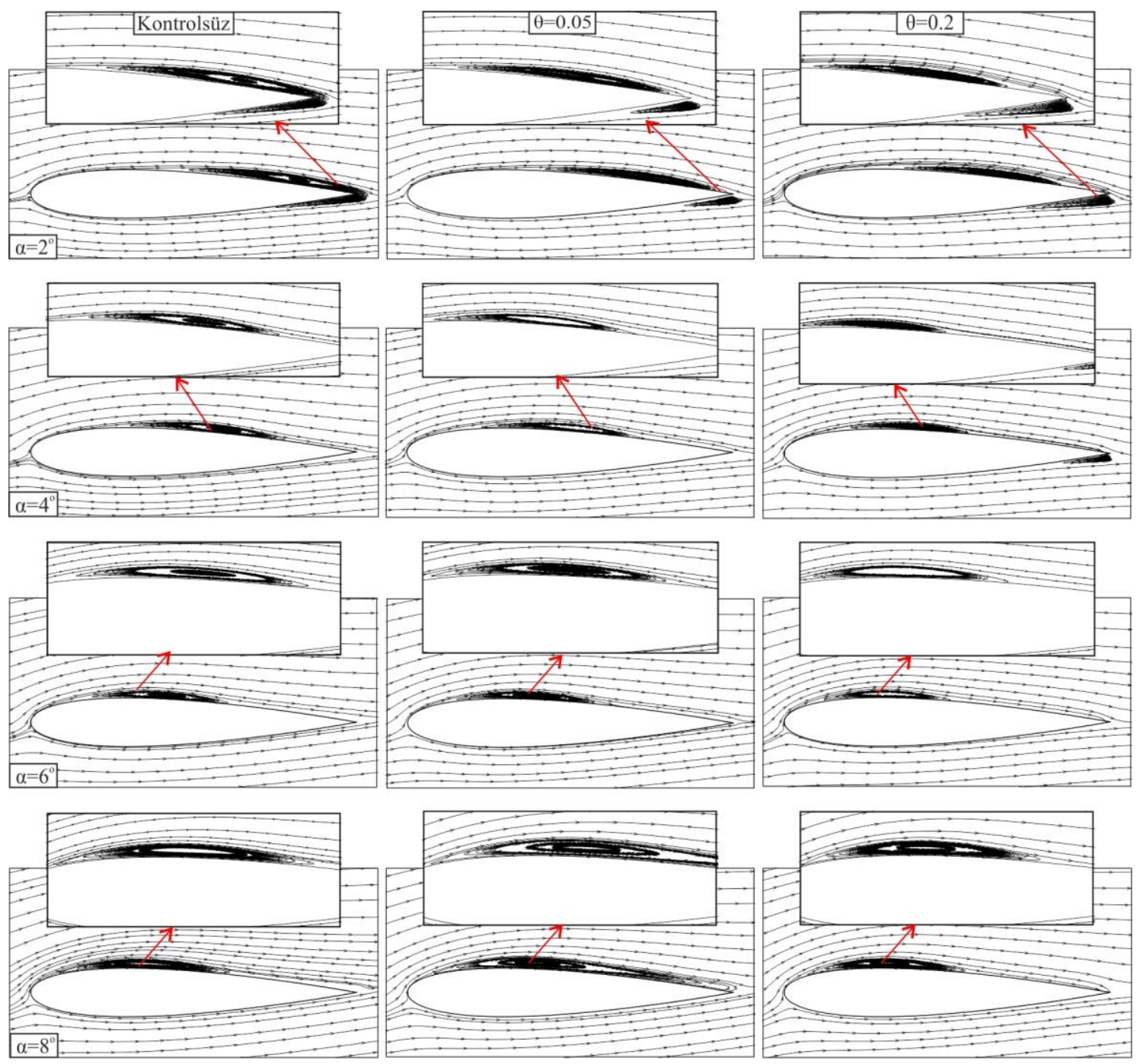

Şekil 5. Farkıı hücum açıları ve akış emme oranları için kanat etrafındaki akım çizgileri

Farklı hücum açıları ve akış emme oranları için akım yönündeki hız bileşeninin serbest akış hızıyla boyutsuzlaştırılmış u/U kontur dağılımları Şekil 6'da sunulmuştur. Elde edilen bulgular kanat firar kenarında uygulan akış emme yöntemin kanat etrafındaki hız dağılımını önemli ölçüde etkilediğini göstermiştir. Hücum açısının $\alpha=6^{\circ}$ değerine kadar artan akış emme oranları ile laminer ayrılma kabarcı̆̆ının kısalarak hücum kenarına yaklaşması hem kanat hücum kenarındaki maksimum hız büyüklüğünün artmasına hem de kayma tabakasının kanat emme yüzeyine yaklaşmasına neden olmuştur. 

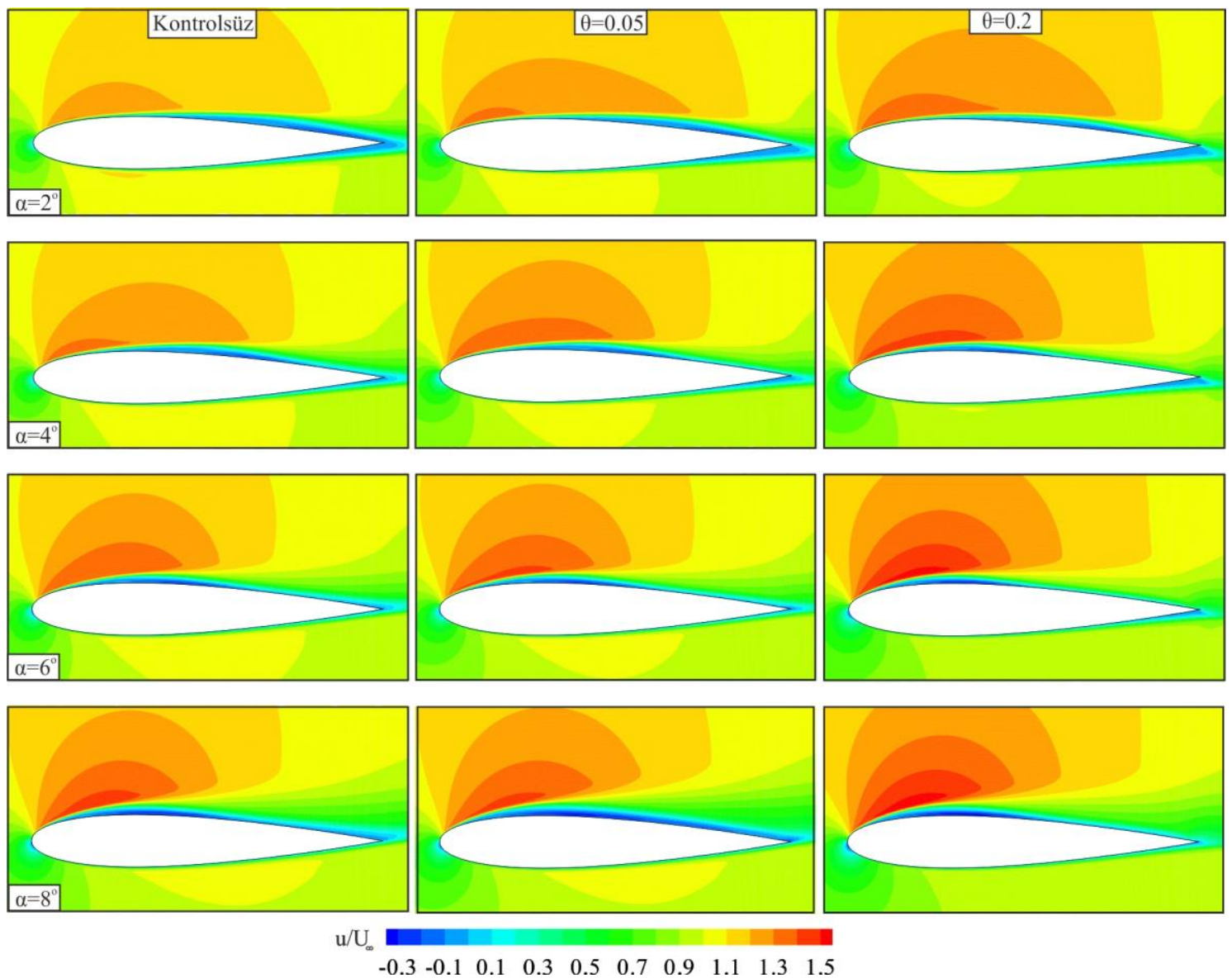

Şekil 6. Farklı hücum açıları ve akış emme oranları için akım yönündeki boyutsuz u hızının dağılımı

\section{SONUÇLAR}

Reynolds sayısının $\mathrm{Re}=48000$ değerinde akış emme yönetimin NACA 0015 kanat profilinin aerodinamik performansı üzerine etkisi sayısal çalışma ile araştırılmıştır. Akış emme işlemi kanat firar kenarından gerçekleştirilmiştir. Sayısal çözümler üç farklı akış emme oranı $(\theta=0.05,0.1$ ve 0.2$)$ için dört farklı hücum açısında $\left(\alpha=2^{\circ}, 4^{\circ}, 6^{\circ}\right.$ ve $\left.8^{\circ}\right)$ için gerçekleştirilmiştir. Sayısal çözümlerde üç denklemli k- $\mathrm{k}_{\mathrm{L}}-\omega$ transition modeli kullanılmıştır. Sayısal çözümlerden elde edilen bulgular artan akış emme oranı ile laminer ayrılma kabarcığının kısaldığını ve hücum kenarına yaklaştığını göstermiştir. Bundan dolayı özellikle düşük hücum açılarında kanat aerodinamik performansı akış emme yöntemi ile önemli ölçüde arttırılıııștr. Ancak akış emme yöntemi $C_{L}$ 'nin artmasının yanı sıra $C_{D}$ 'nin de artmasına neden olduğu için yüksek hücum açısında $\left(\alpha=8^{\circ}\right) C_{L} / C_{D}$ oranının kontrolsüz duruma göre önemli ölçüde değişmediği gözlemlenmiştir. Sonuç olarak akış emme yönteminin düşük hücum açılarında NACA 0015 kanat profilinin aerodinamik performansını arttırmada başarılı olduğu görüşülmüş̧ür.

\section{KAYNAKLAR}

[1] Ricci, R., \& Montelpare, S. (2005). A quantitative IR thermographic method to study the laminar separation bubble phenomenon. International Journal of Thermal Sciences, 44, 709-719.

[2] Zhang, W., Hain, R., \& Kähler, C. J. (2008). Scanning PIV investigation of the laminar separation bubble on a SD7003 airfoil. Experiments in Fluids, 45, 725-743.

[3] Genç, M. S., Karasu, İ., \& Açıkel, H. H. (2012). An experimental study on aerodynamic of NACA2415 aerofoil at low Re numbers. Experimental Thermal and Fluid Science, 39, 252-264.

[4] Juanmian, L., Feng, G., \& Can, H. (2013). Numerical study of separation on the trailing edge of a symmetrical airfoil at a low Reynolds number. Chinese Journal of Aeronautics, 26(4), 918-925. 
[5] Demir, H., \& Genç, M. S. (2017). An experimental investigation of laminar separation bubble formation on flexible membrane wing. European Journal of Mechanics / B Fluids, 65, 326-338.

[6] Genç, M. S., Karasu, İ., Açıkel, H. H., \& Akpolat, M. T. (2012). Low Reynolds Number Flows and Transition, Low Reynolds Number Aerodynamics and Transition. IntechOpen, 3-28.

[7] Huang, L., Huang, P. G., \& LeBeau, R. P. (2004). Numerical study of blowing and suction control mechanism on NACA0012 airfoil. Journal of Aircraft, 41(5), 1005-1013.

[8] Johari, H., Henoch, C., Custodio, D., \& Levshin, A. (2007). Effect of leading-edge protuberances on airfoil performance. AIAA Journal, 45(11), 2634-2642.

[9] Genç, M. S., Kaynak, Ü., \& Yapici, H. (2011). Performance of transition model for predicting low Re aerofoil flows without/with single and simultaneous blowing and suction. European Journal of Mechanics / B Fluids, 30, 218-235.

[10] Yousefi, K., \& Saleh, R. (2014). The effect of trailing edge blowing on aerodynamic characteristics of the NACA 0012 airfoil and optimization of the blowing slot geometry. Journal of Theoretical and Applied Mechanics, 52(1), 165-179.

[11] Açıkel, H. H. \& Genç, M. S. (2016). Flow control with perpendicular acoustic forcing on NACA 2415 aerofoil at low Re numbers. Proceedings of the Institution of Mechanical Engineers, Part G: Journal of Aerospace Engineering, 230(13), 2447-2462.

[12] Genç, M. S., Açıkel, H. H., Akpolat, M. T., Özkan, G. \& Karasu, İ. (2016). Acoustic control of flow over NACA 2415 airfoil at low Reynolds numbers. Journal of Aerospace Engineering 29(6), 1-19.

[13] Siozos-Rousoulis, L., Chris, L., \& Ghader, G. (2017). A flow control technique for noise reduction of a rod-airfoil configuration. Journal of Fluids and Structures, 69, 293-307.

[14] Akbiyık, H., Yavuz, H., \& Akansu, Y. E. (2017). Comparison of the linear and spanwise-segmented DBD plasma actuators on flow control around a NACA 0015 airfoil. IEEE Transactions on Plasma Science, 45(11), 2913-2921.

[15] Akbıyık, H., Yavuz, H., \& Akansu, Y. E. (2018). A study on the plasma actuator electrode geometry configuration for improvement of the aerodynamic performance of an airfoil. Strojniski Vestnik/Journal of Mechanical Engineering, 64 (12), 719-725.

[16] Açıkel, H. H. \& Genç, M. S. (2018). Control of laminar separation bubble over wind turbine airfoil using partial flexibility on suction surface. Energy, 165, 176-190.

[17] Genç, M. S., Koca, K., \& Açıkel, H. H. (2019). Investigation of pre-stall flow control on wind turbine blade airfoil using roughness element. Energy, 176, 320-334.

[18] Walters, D. K., \& Cokljat, D. (2008). A three-equation eddy-viscosity model for Reynolds-averaged Navier-Stokes simulations of transitional flow. ASME. Journal of Fluids Engineering, 130(12), 1-14.

[19] Fluent, A.N.S.Y.S. (2016). Ansys Fluent Theory Guide. ANSYS Inc, USA.

[20] Genç, M. S., Kaynak, Ü., \& Lock, G. D. (2009). Flow over an aerofoil without and with a leading-edge slat at a transitional Reynolds number. Proceedings of the Institution of Mechanical Engineers, Part G: Journal of Aerospace Engineering, 223(3), 217-231.

[21] Choudhry, A., Arjomandi, M., \& Kelso, R. (2015). A study of long separation bubble on thick airfoils and its consequent effects. International Journal of Heat and Fluid Flow, 52, 84-96. 